\title{
Effect of Delayed Bonding and Different Antioxidants on Composite Restoration Microleakage of Internally Bleached Teeth
}

\author{
Ameer A Al-Hassani ${ }^{1 *}$ and Abdulla MW Al-Shamma ${ }^{2}$ \\ ${ }^{1}$ Department of Conservative Dentistry, University of Baghdad, Iraq \\ ${ }^{2}$ Assistant Professor, Department of Conservative Dentistry, University of Baghdad, Iraq
}

Submission: May 11, 2018; Published: June 07, 2018

*Corresponding author: Ameer Adnan Al-Hassani, M.Sc. student, Department of Conservative Dentistry, College of Dentistry, University of Baghdad, Iraq Email: ameera.altabatabiee@uokufa.edu.iq

\begin{abstract}
Background: Bleaching the discolored teeth may affect the sealing ability of immediately placed composite resin restoration. The aim of this in vitro study was to evaluate and compare the neutralizing effect of delayed bonding and different antioxidant agents on the microleakage of composite restoration in endodontically treated teeth after intracoronal bleaching with hydrogen peroxide.

Materials and methods: Following endodontic therapy, 60 sound human mandibular 2nd premolar teeth of comparable sizes were randomly divided into six groups, each of 10 samples ( $\mathrm{n}=10$ ). Except Group A (negative control), all samples in the other groups were exposed to internal bleaching with 35\% hydrogen peroxide (Opalescence ${ }^{\circledR}$ Endo "walking" bleach) that placed into the pulp chamber for 5 days. For Group $\mathrm{B}$, the samples were immediately bonded after bleaching. Group C, the bonding procedure was delayed 2 weeks after bleaching. Groups D, E and F, the samples treated with $10 \%$ Sodium Ascorbate (SA), $10 \%$ Green Tea (GT) and 10\% Pine Bark (PB) respectively and then restored immediately. In all groups, the access cavities were restored using Scotchbond ${ }^{\mathrm{TM}}$ Universal Adhesive and Filtek ${ }^{\mathrm{TM}}$ Bulk Fill posterior restorative composite resin. Teeth were subjected to 500 thermal cycles and immersed in $2 \%$ methylene blue for 1 day. Teeth were sectioned longitudinally from buccal to lingual direction, passing through the center of the restoration, using a diamond disk. The samples were examined under stereomicroscopic magnification (40X). Microleakage was assessed with a $0-4$ scoring system and analyzed using nonparametric statistical methods $(\alpha=0.05)$.
\end{abstract}

Results: Internal bleaching with $35 \%$ hydrogen peroxide gel for 5 days resulted in significant $(p>0.01)$ increase in microleakage of composite resin restorations when bonding was performed immediately after bleaching (Group B). No significant difference ( $p>0.05$ ) was found between negative control group (Group A) and group that bonded after 14 days after bleaching (Group C). Furthermore, there was no significant difference among groups that bonded after treatment with $10 \%$ of antioxidant materials (D, E and F) when compared to each other, and when compared to control group (Group A).

Conclusion: The use of antioxidants effectively reversed the compromised sealing ability of composite filling to bleached dental tissue and all the antioxidants used in this study was equally effective to neutralize the adverse effects of hydrogen peroxide on microleakage of immediately restored teeth.

Keywords: Bleaching; Microleakage; Green Tea; Pine Bark; Sodium Ascorbate

\section{Introduction}

Discolored anterior teeth are often perceived as an esthetic detraction, where esthetic of anterior teeth is an important approach in the modern dentistry [1]. The coronal portion of the tooth consists of enamel, dentine and pulp. Any change to these structures is likely to cause an alteration in the outward appearance of the tooth caused by its light transmitting and reflecting properties [2]. The causes of tooth discoloration are varied and complex but are usually classified as being either intrinsic, extrinsic or internalized in nature. Stains within the dentine or intrinsic discoloration often results from systemic or pulpal origin [3]. The bleaching of discolored endodontically treated teeth has become increasingly important in recent years. In the middle of the $19^{\text {th }}$ century, the first attempts were made to lighten discolored teeth using various agents. Initially, oxalic acid was used, until the tooth bleaching effect of hydrogen peroxide was discovered in 1884 [4]. Hydrogen peroxide or its derivatives are used in various concentrations in most bleaching techniques [5].

The use of dental bleaching agents has various side effects, such as pulpal sensitivity, changes in the tooth structure, 
microleakage in pre-and-post placed composite restorations and external root resorption [6]. A decrease in the adhesion of different restorative materials following bleaching of enamel and dentine has also been reported [7]. Various theories have been proposed to explain the adverse effect of bleaching on composite resin to teeth. Bleaching with hydrogen peroxide may result in significant decrease of enamel and dentin calcium and phosphate content and in morphological alteration in the most superficial enamel crystallites [8,9]. Other author speculated that residual peroxide and/or oxygen radicals in bleached teeth interfere with the polymerization of adhesive restorative material and decrease bond strength [10].

Several methods have been proposed to minimize these problems, such as removal of the superficial enamel layer, pretreatment of bleached enamel with alcohol, use of adhesives containing organic solvents, cavity cleansing with catalase or sodium ascorbate antioxidant, and a post-bleaching waiting period ranging from 24 hours to three weeks [11].

The most common of these methods is to delay any bonding procedure for 2-3 weeks after bleaching [10]. These recommendations are based on reports that the effect of free radicals of bleaching material on enamel or dentin after bleaching treatments is temporary.

\section{Materials and Methods}

Sixty sound human mandibular second premolar teeth of comparable sizes, extracted for orthodontic purposes. The samples were divided into six groups, each of 10 specimens: (A) Negative control group (no bleaching), (B) Positive control group (immediate restoration) after bleaching, (C) Delayed restoration after bleaching and antioxidant materials after bleaching which involve the three remaining groups, (D) $10 \%$ green tea, (E) $10 \%$ pine bark and (F) 10\% sodium ascorbate as shown in Table 1.

Table 1: Samples Grouping.

\begin{tabular}{|c|c|c|c|}
\hline Groups & Bleaching & $\begin{array}{c}\text { Time of } \\
\text { Bonding } \\
\text { Immediate }\end{array}$ & $\begin{array}{c}\text { Antioxidant } \\
\text { Treatment }\end{array}$ \\
\hline A & No & Immediate & No \\
\hline B & $\begin{array}{c}\text { Bleached with } 35 \% \\
\mathrm{H}_{2} \mathrm{O}_{2}\end{array}$ & Immediate & No \\
\hline C & $\begin{array}{c}\text { Bleached with } 35 \% \\
\mathrm{H}_{2} \mathrm{O}_{2}\end{array}$ & After 14 days & $10 \%$ Sodium \\
D & $\begin{array}{c}\text { Bleached with } 35 \% \\
\mathrm{H}_{2} \mathrm{O}_{2}\end{array}$ & Immediate & $10 \%$ Green Tea \\
\hline E & $\begin{array}{c}\text { Bleached with } 35 \% \\
\mathrm{H}_{2} \mathrm{O}_{2}\end{array}$ & Immediate & $10 \%$ Pine Bark \\
\hline F & $\begin{array}{c}\text { Bleached with } 35 \% \\
\mathrm{H}_{2} \mathrm{O}_{2}\end{array}$ & Immediate & \multicolumn{2}{|c|}{} \\
\hline
\end{tabular}

Access openings $(3 \mathrm{~mm} \times 3 \mathrm{~mm})$ were made using round diamond bur for entrance and endodontic fissure bur for completion of cavity in a high-speed headpiece under cooling with water/air. For all teeth, endodontic treatment were performed and the canals will be prepared, using Rotary Protaper Universal files (Dentsply, Switzerland) and obturated with single cone gutta-percha of the accordance size and resin based sealer (META BIOMED Co., Ltd., Cheongwon, Korea). The excess coronal guttapercha was thermally cut beyond the orifice to provide space for placing $2 \mathrm{~mm}$ thickness of self-cured glass ionomer restorative material (SDI, Australia), over the root filling.

\section{Bleaching procedure}

All teeth (except group A) were subjected to bleaching procedure by using Opalescence ${ }^{\circledR}$ Endo (Ultardent, USA) which is $35 \%$ Hydrogen Peroxide (HP). $0.1 \mathrm{ml}$ of the material was delivered to the pulp chamber and was sealed with a Olitemp C temporary cement (Olident, Germany). The samples were stored for five days in an incubator at $370 \mathrm{C}$ and $100 \%$ relative humidity, according to the manufacturing instructions.

\section{Delayed bonding}

For (Group C), after removal of bleaching material, the samples were stored in distilled water for 2 weeks before restoration.

Antioxidant preparation and application: In Groups (D, E, and F) bleaching was followed by treatment with antioxidants $10 \%$ sodium ascorbate solution, $10 \%$ green tea extract solution, and $10 \%$ pine bark extract solution respectively. To prepare $10 \%$ of antioxidant solution, $10 \mathrm{~g}$ of the material was dissolved in $100 \mathrm{ml}$ of distilled water at 370C. The antioxidant solution delivered into the access cavity and left for 30 minutes. After that, it was removed by rinsing the cavity with deionized water for 2 minutes.

\section{Restorative procedure}

All access cavities were bonded using Etch and Rinse technique. Etching was performed using with $32 \%$ phosphoric acid for 15 seconds, rinsed thoroughly for 30 second and blot dried; then the adhesive (Scotchbond ${ }^{\mathrm{TM}}$ Universal Adhesive) was applied and rubbed on the etched surface for 20 second and light-cured for 10 seconds using LED curing device (Perfection plus, U.K.).

Resin composite (Filtek ${ }^{\mathrm{TM}}$ Bulk Fill Posterior Restorative) was used to fill the cavity by placing two layers each of $3.5 \mathrm{~mm}$ thickness and light cured for 40 seconds.

\section{Thermaocycling procedure}

The bonded specimens were subjected to 500 thermal cycles between water baths of 5 and $55 \mathrm{C}$ with a dwell time of 30 seconds.

Microleakage test: The specimens were covered with two coats of nail varnish except $1 \mathrm{~mm}$ around the tooth-restoration interface and the root apices were sealed with inlay wax. After immersion in $2 \%$ methylene blue for 1 day, the teeth were washed in tap water, and the nail varnish and the wax was removed with a scalpel. The teeth were sectioned longitudinally from labial to lingual direction passing through the center of the restoration using a low-speed diamond disc. Microleakage was assessed by using a stereomicroscope at (40X). The two halves of each sectioned sample were examined buccally and lingually at the tooth (Figure 1). 


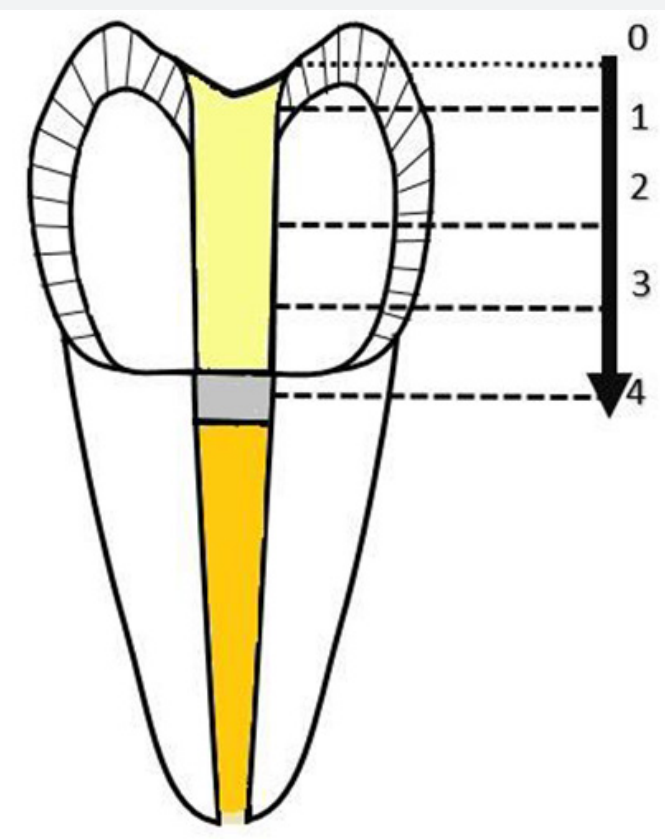

0 : No dye penetration.

1: Dye penetration only within the enamel.

2: Dye penetration up to half of the cavity depth.

3: Dye penetration greater than score 2 without involvement of gutta-percha.

4: Dye penetration with involvement of gutta-percha.

Figure 1: Criteria for evaluating microleakage scores.

The microleakage data were analyzed by Kruskal-Wallis and Mann-Whitney U tests. All statistical analyses were performed using SPSS 20.

\section{Results}

The results of descriptive statistics revealed that the highest microleakage mean value was observed in group B (1.7) and the lowest in group A (0.2) as shown in Figure 2.

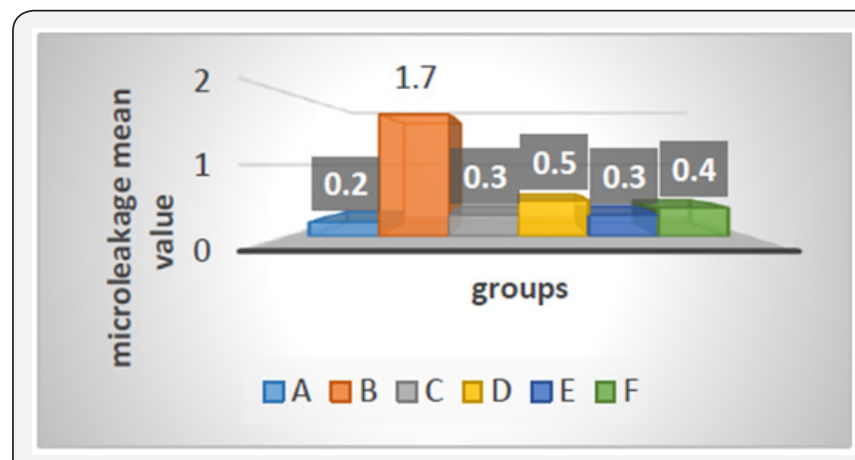

Figure 2: bar chart showing the microleakage mea values for each group.

Mann Whitney U test revealed that, group B (immediate bonding) showed a significantly higher microleakage ( $\mathrm{p}=0.003)$ than group A (negative control group) (Table $2 \& 3$ ).
Table 2: Comparison of negative control group (A) and positive control group (B) using Mann-Whitney U test (SPSS Inc., Chicago, IL, USA) at a significance level of 0.05 .

\begin{tabular}{|c|c|c|c|c|}
\hline Group & Mean rank & $\begin{array}{c}\text { Mann- } \\
\text { Whitney U }\end{array}$ & p-value & Sig. \\
\hline A & 6.9 & 14 & 0.003 & HS* \\
\hline B & 14.1 & & & \\
\hline
\end{tabular}

${ }^{*} \mathrm{HS}$ : Highly significant difference $(p<0.01)$.

Sig.: Significant difference

Table 3: Kruskal-Wallis test involving the negative control group (A) and the test groups $(\mathrm{C}-\mathrm{F})$.

\begin{tabular}{|c|c|c|c|}
\hline Groups & Mean Rank & P-Value & Sig. \\
\cline { 1 - 2 } B & 7.15 & \multirow{2}{*}{0.006} & HS \\
\cline { 1 - 2 } C & 13.85 & \multirow{2}{*}{0.019} & Sig. \\
\cline { 1 - 2 } B & 7.55 & \multirow{2}{*}{0.006} & HS \\
\cline { 1 - 2 } D & 13.45 & & Sig. \\
\cline { 1 - 2 } B & 7.1 & \multirow{2}{*}{0.011} & \\
\hline E & 13.9 & & \\
\hline B & 13.7 &
\end{tabular}

Kruskal-Wallis test showed that, there was no significant difference ( $p>0.05$ ) between group A (negative control group) and group C (delayed bonding) as well as the antioxidant treated groups (D-F) as shown in Table 3. Kruskal-Wallis test, also showed a highly significant difference when the experimental groups (CF) were compared to the positive control group (Group B). MannWhitney $\mathrm{U}$ test was used to assess the source of the difference. The results showed a highly significant difference $(p<0.01)$ in microleakage between group B (BL. + immed. Bond) and group C (BL. + Del. Bond), and between group B and group E (BL. + G.T.).

In addition, there was a significant difference $(0.05>p>0.01)$ between group B and group D (BL.S.A.); and between group B and group F (BL. + P.B.) as shown in Table 4.

Table 4: Mann whitney test between positive control group (B) and the experimental groups (C-F).

\begin{tabular}{|c|c|c|c|}
\hline Groups & Mean Rank & P-Value & Sig. \\
\hline A & 22.8 & & \\
\cline { 1 - 2 } C & 23.55 & & \\
\cline { 1 - 2 } D & 28.35 & \multirow{2}{*}{0.783} & NS* \\
\hline E & 25.2 & & \\
\hline F & 27.6 & & \\
\hline
\end{tabular}

Sig.: Significant difference

NS: No significant difference 
From the results of Kruskal-Wallis test shown in the Table 3, there was no significant difference among the delayed bonding group (c) and the antioxidant treated groups (D-F), as well as among the antioxidant treated groups together (Figure 3).
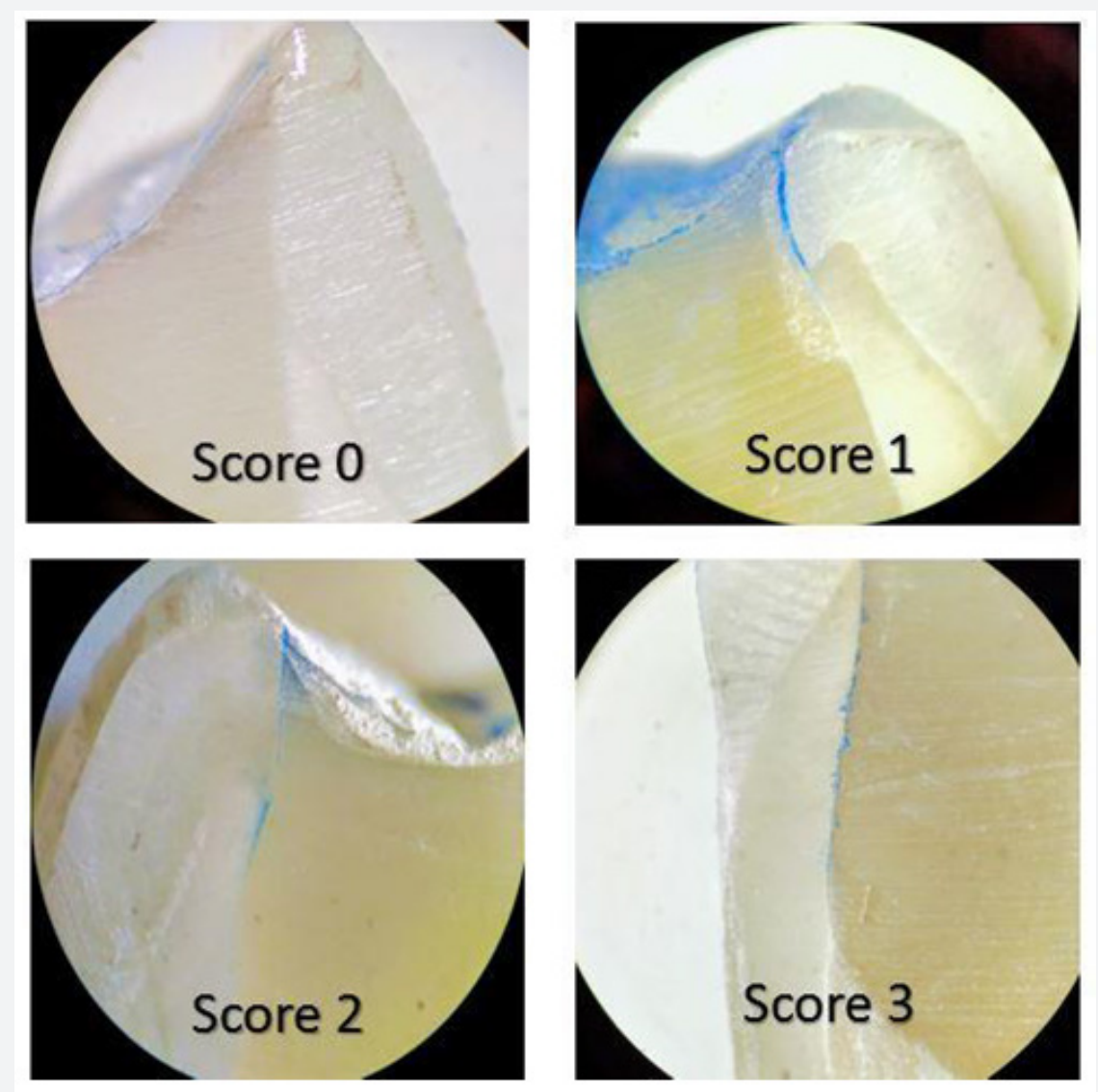

Figure 3: Microleakage depth of penetration scores.

\section{Discussion}

It is obvious from the results of this study that composite restorations which were immediately bonded to bleached samples in (Group B), showed highly significant increase in the microleakage compared to those restorations in the unbleached samples (Group A). This mean that immediate bonding after intracoronal bleaching produces incomplete sealing of composite restoration. This may be due to the presence of residual peroxide and oxygen in the enamel and dentine, which can interfere with resin attachment and inhibit resin polymerization.

In enamel, a SEM examination of interface between bleached enamel and resin suggested presence of defective resin tags which penetrate lesser depth than unbleached surface [12]. SEM examinations of interfaces between resin and bleached enamel displayed a granular and porous aspect with a bubbled appearance. It has been suggested that they may be due to gaseous bubbling, which could be the result of oxidizing reactions due to the entrapment of peroxide in the subsurface layer of the enamel [13].
In dentine, it has been suggested that the decrease in microleakage might be attributed to the accumulation of oxygen in dentin, since dentin acts as an oxygen reservoir. The release of oxygen might interfere with resin infiltration into etched dentin or polymerization of resins that cure via a free-radical mechanism [14].

In this study, when the specimens were bleached and stored 14 days in DDW then bonded with composite (Group C), increase in the sealing ability of the restoration up to the level obtained in the non-bleached control (Group A) was reached. Khoroushi et al. [6] suggested, a certain waiting period is required to allow a gradual elimination of residual oxygen from the bleached surface before adhesive restoration [15]. This may be due to that immersion in water causes dispersion of residual oxygen remains in the enamel and dentin matrix. Another explanation is that hydrogen peroxide is extremely unstable, losing its activity after some time [16].

Many studies reported that the application of $10 \%$ sodIum Ascorbate (SA) antioxidant into the access cavity of intracoronallybleached tooth allows immediate composite restoration after 
nonvital bleaching through its ability to remove oxygen radicals $[15,17]$. However, sodium ascorbate has been found to be mutagenic for mammalian somatic cells [18].

Green tea is made from the Camellia sinensis plant. It contains flavanoids or catechins, such as epigallocatechin gallate (EGCG) [19]. Green tea catechins have shown to possess potent antioxidant activity that is several times higher than that of vitamins $\mathrm{C}$ and $\mathrm{E}$ [20]. In recent years, the use of $10 \%$ green tea has been studied as an antioxidant material after dental bleaching. Additionally, green tea is a natural product, cheap and with an extended shelf life which could be an option for use after bleaching [21].

Pine bark extract contain oligomeric-proanthocyanidins that are a class of polyphenolic bioflavonoids found in fruits and vegetables which have free radical scavenging and antioxidant activity. They also have antibacterial, antiviral, anti-inflammatory, antiallergic, anticarcinogenic, and vasodilatory actions [22]. Some in vitro studies observed that $10 \%$ pine bark extract was useful reversing the effect of free radicals on bleached enamel [23]. However, to date no study compared those materials together.

In the present study, treatment with $10 \%$ of either antioxidant solution (Group D-F), resulted in leakage score with no that there was no significant difference in microleakage when compared with negative control group (Group A). This indicates that the sealing ability of the composite restoration of the bleached and antioxidant treated teeth was reversed to the value of unbleached teeth.

Antioxidants act by ending the electron stealing reaction of free radicals, by donating one of their electrons, although, they not become a free radical by donating an electron because they are stable in either form. In another word, they act by scavenging or chain breaking, where they intercept radical chain and break the oxidizing reaction by trapping peroxyl and other reactive oxygen free radicals [24].

These study results are consistent with previous studies, that claimed the use of antioxidant material are useful in reversing the adverse effect of the bleaching material on the microleakage of composite restorations [25,26].

The study findings were also supported by many researchers, who stated that these materials were able to restore the bond strength of the bleached teeth to the level of unbleached one $[1,13,27,28]$. The results also showed that there were no significant differences among the antioxidant treated groups (DF) when compared to each other. These findings indicate that all these antioxidant materials (sodium ascorbate, green tea and pine bark) are equally effective in neutralizing the deleterious effect of bleaching on the microleakage of composite resin.

The study results were supported by previous researches which compared between two of these materials. Two of these studies showed that there is no significant difference in bond strength when the bleached samples treated with sodium ascorbate and green tea, and both materials were able to neutralize the negative effect of bleaching on composite restorations [21,29,30]. Subramonian, Mathai [23] stated that, there was no significant difference in bond strength of the groups treated with sodium ascorbate and pine bark.

\section{Conclusion}

Under the limitation of this in vitro study, the following conclusions were obtained:

a) Immediate restoration of bleached enamel and dentine with $35 \%$ hydrogen peroxide gel for 5 days, resulting in marked increase in microleakage of composite resin restoration, which performed immediately after bleaching.

b) Delaying the bonding of composite resin to the bleached teeth for 14 days was enough to get rid of the adverse effect of bleaching agent on the microleakage of composite restoration.

c) Treatment of the bleached teeth with $10 \%$ sodium ascorbate, $10 \%$ green tea and $10 \%$ pine bark antioxidant in solution forms for 30 minutes can neutralize the deleterious effect of bleaching material on the microleakage of immediately placed composite restoration.

\section{References}

1. Khoroushi M, S Aghelinejad (2011) Effect of postbleaching application of an antioxidant on enamel bond strength of three different adhesives. Med Oral Patol Oral Cir Bucal 16(7): e990-e996.

2. Addy M, J Moran (1995) Mechanisms of stain formation on teeth, in particular associated with metal ions and antiseptics. Advances in Dental Research 9(4): 450-456.

3. Sulieman M (2005) An overview of tooth discoloration: extrinsic, intrinsic and internalized stains. Dental update 32(8): 463-4,466-8, 471.

4. Goldstein R (1997) In-office bleaching: where we came from, where we are today. The Journal of the American Dental Association 128: 11S-15S.

5. Heymann HO, EJ Swift Jr, AV Ritter (2014) Sturdevant's art \& science of operative dentistry, Elsevier Health Sciences, Mosby, USA, pp. 568.

6. Khoroushi M, T Saneie (2012) Post-bleaching application of an antioxidant on dentin bond strength of three dental adhesives. Dent Res J (Isfahan) 9(1): 46-53.

7. Demarco F, Freitas JM, Silva MP, Justino LM (2001) Microleakage in endodontically treated teeth: influence of calcium hydroxide dressing following bleaching. International endodontic journal 34(7): 495-500.

8. Basting R, A Rodrigues, M Serra (2005) The effect of $10 \%$ carbamide peroxide, carbopol and/or glycerin on enamel and dentin microhardness. Operative Dentistry, University of Washington, USA 30(5): 608 .

9. Fu B, W Hoth-Hannig, M Hannig (2007) Effects of dental bleaching on micro- and nano-morphological alterations of the enamel surface. Am J Dent 20(1): 35-40. 
10. Shinohara MS, Alessandra Rezende Peris, Luiz André Freire Pimenta, Glaucia Maria Bovi Ambrosano (2005) Shear bond strength evaluation of composite resin on enamel and dentin after nonvital bleaching. Journal of Esthetic and Restorative Dentistry 17(1): 22-29.

11. Attin T, Hannig C, Wiegand A, Attin R (2004) Effect of bleaching on restorative materials and restorations-a systematic review. Dent Mater 20(9): 852-861.

12. Mazaheri H, Maryam Khoroushi, Ehsan Shafiei, Reza Ghorbanipour, Fateme Majdzade (2011) Bond strength of composite-resin and resinmodified glass ionomer to bleached enamel: delay bonding versus an antioxidant agent. Indian Journal of Dental Research 22(3): 432-435.

13. Türkün M, A Kaya (2004) Effect of $10 \%$ sodium ascorbate on the shear bond strength of composite resin to bleached bovine enamel. J Oral Rehabil 31(12): 1184-1191.

14. Kimyai S, H Valizadeh (2008) Comparison of the effect of hydrogel and a solution of sodium ascorbate on dentin-composite bond strength after bleaching. J Contemp Dent Pract 9(2): 105-112.

15. Khoroushi M, A Feiz, M Ebadi (2009) Influence of intermediary filling material on microleakage of intracoronally bleached and restored teeth. Dental research journal 6(1): 17-22.

16. Hardman PK, D Moore, G Petteway (1985) Stability of hydrogen peroxide as a bleaching agent. General Dentistry 33(2): 121.

17. Cavalli V, Reis AF, Giannini M, Ambrosano GM (2001) The effect of elapsed time following bleaching on enamel bond strength of resin composite. Oper dent 26(6): 597-602.

18. Perumalla A, NS Hettiarachchy (2011) Green tea and grape seed extracts-Potential applications in food safety and quality. Food Research International 44(4): 827-839.

19. Chan EW, Soh EY, Tie PP, Law YP (2011) Antioxidant and antibacterial properties of green, black, and herbal teas of Camellia sinensis. Pharmacognosy res 3(4): 266.

20. Rice evans CA, Nicholas J Miller, Paul G Bolwell, Peter M Bramley, John B Pridham (1995) The relative antioxidant activities of plant-derived polyphenolic flavonoids. Free radical research 22(4): 375-383.
21. Ozelin A, Ricardo Danil Guiraldo, Rodrigo Varella de Carvalho, Murilo Baena Lopes, Sandrine Bittencourt Berger (2014) Effects of green tea application time on bond strength after enamel bleaching. Brazilian dental journal 25(5): 399-403.

22. Fine AM (2000) Oligomeric proanthocyanidin complexes: history, structure, and phytopharmaceutical applications. Alternative medicine review: a journal of clinical therapeutic 5(2): 144-151.

23. Subramonian R, Mathai V, Christaine Angelo JB, Ravi J (2015) Effect of three different antioxidants on the shear bond strength of composite resin to bleached enamel: An in vitro study. Journal of Conservative Dentistry 18(2): 144 .

24. Perchyonok V, S Grobler (2015) Tooth-bleaching: mechanism, biological aspects and antioxidants. Int J Dent Oral Hlth.

25. Moosavi H, Moghaddas MJ, Ghoddusi J, Rajabi O (2010) Effects of two antioxidants on the microleakage of resin-based composite restorations after nonvital bleaching. J Contemp Dent Pract 11(6): E033-E040.

26. Park JY, TY Kwon, YK Kim (2013) Effective application duration of sodium ascorbate antioxidant in reducing microleakage of bonded composite restoration in intracoronally-bleached teeth. Restor Dent Endod 38(1): 43-47.

27. Garcia EJ, Tatiane Luiza Cadorin Oldoni, Severino Matias de Alencar, Alessandra Reis, Alessandro D Loguercio, et al. (2012) Antioxidant activity by DPPH assay of potential solutions to be applied on bleached teeth. Brazilian dental journal 23(1): 22-27.

28. Al Bayaty AM, II Al Rawi (2013) The effect of anti-oxidant agents as neutralizers of bleaching agents on dentin bond strength. Journal of Baghdad College of Dentistry 25(2): 18-23.

29. Sharafeddin F, M Motamedi, S Modiri (2013) Effect of Immediate Application of Pomegranate Peel, Grape Seed and Green Tea Extracts on Composite Shear Bond Strength of In-Offiee Bleached Enamel. Research Journal of Biological Sciences 8(3): 83-87.

30. Khamverdi Z, Khadem P, Soltanian A, Azizi M (2016) In-Vitro Evaluation of the Effect of Herbal Antioxidants on Shear Bond Strength of Composite Resin to Bleached Enamel. Journal of Dentistry of Tehran University of Medical Sciences 13(4): 244-251.

\section{Your next submission with Juniper Publishers will reach you the below assets}

- Quality Editorial service

- Swift Peer Review

- Reprints availability

- E-prints Service

- Manuscript Podcast for convenient understanding

- Global attainment for your research

- Manuscript accessibility in different formats

( Pdf, E-pub, Full Text, Audio)

- Unceasing customer service

Track the below URL for one-step submission https://juniperpublishers.com/online-submission.php 